\title{
Interação social em ambiente virtual de ensino e aprendizagem e sua contribuição no desempenho dos cursistas em uma formação continuada a distância
}

\author{
Fernandez B. Jany ${ }^{1}$, Cruz, Dulce Márcia ${ }^{2}$ \\ ${ }^{1}$ Divisão de Tecnologia Educacional, Superintendência de Gestão de Políticas \\ Educacionais, Secretaria Municipal de Educação de Campo Grande (MS). \\ ${ }^{2}$ Departamento de Metodologias de Ensino, Programa de Pós-graduação em Educação, \\ Centro de Ciências da Educação, Universidade Federal de Santa Catarina. \\ \{janybaena, dulce.marcia\}@gmail.com
}

\begin{abstract}
Resumo. $O$ objetivo principal desta pesquisa foi investigar se a interação social no ambiente virtual contribui para o desempenho e motivação dos cursistas em uma formação continuada a distância para professores da rede municipal de educação de Campo Grande/MS. A pesquisa se caracteriza como um estudo de caso de abordagem quali-quantitativa com objetivos descritivos e explicativos. Diante da análise dos resultados, constatados pela observação direta no ambiente, pela entrevista com professores mediadores e pelo questionário aplicado aos cursistas, concluiu-se que a interação social permeia todo o processo de aprendizagem, contribuindo para o desempenho dos cursistas e a produção coletiva e colaborativa.
\end{abstract}

\begin{abstract}
The main objective of this research was to investigate if social interaction in the virtual environment contributes to the performance and motivation in a continuing education distance course for teachers from the municipal education Campo Grande / MS forum. The research is characterized as a case study qualitative and quantitative approach with descriptive purposes and explanatory. After analyzing the results, recorded by direct observation in the environment, the interview with teachers and for questionnaire administered to participants, it was found that the interaction permeates the entire learning process, contributing to the performance of the course participants and the collective production and collaborative.
\end{abstract}

\section{Introdução}

Entre 2011 e 2013, a Divisão de Tecnologia Educacional da Secretaria Municipal de Educação, de Campo Grande - MS ofereceu o curso Ambiente Virtual de Aprendizagem - AVA no contexto da Aprendizagem e Avaliação com o objetivo de propiciar formação continuada aos Coordenadores de Suporte Pedagógico de Tecnologia (CSPTEC) da Rede Municipal de Educação (REME). Os CSPTEC são professores que atuam na gestão do uso das Tecnologias da Informação e Comunicação 
(TIC) buscando ampliar o êxito na aprendizagem dos alunos da REME, bem como proporcionar à comunidade escolar a fluência tecnológica necessária à sociedade contemporânea. O curso, estruturado em 160h, distribuídas em nove módulos, com atividades teóricas e práticas presenciais e a distância. Foi oferecido no período de oito meses, por meio do ambiente virtual Moodle.

Nas atividades a distância, professores mediadores acompanharam diária e sistematicamente os trabalhos dos cursistas, propondo produções textuais coletivas e colaborativas, o que pressupõe uma aprendizagem mais significativa, que envolve atividades de interação entre os partícipes. Esta situação despertou o interesse em realizar um estudo sobre a contribuição da troca de informações, ou seja, a interação entre os partícipes do referido curso.

A justificativa para essa pesquisa está nos estudos, principalmente de Vygotski, (2010), para quem a interação social influencia potencialmente o desenvolvimento individual das pessoas, pois segundo o autor, o ser humano é compreendido no seu "eu", ou seja, na sua individualidade, por meio das relações que estabelece no social. A interação e a aprendizagem possuem assim uma relação estreita, concretizada por meio da linguagem.

Nesta perspectiva, foram elaboradas as seguintes questões que guiaram a pesquisa: A interação contribui para o desempenho dos alunos, bem como para a produção coletiva e colaborativa em um curso de formação continuada de professores?

Buscando responder essas questões, o objetivo geral desta pesquisa, concluída em forma de uma monografia de especialização (FERNANDEZ, 2013), foi investigar como se dá a interação social num ambiente virtual de ensino e aprendizagem, se ela contribui para o desempenho de alunos e para a produção coletiva e colaborativa, em um ambiente virtual de ensino e aprendizagem no curso de formação continuada, oferecido para os professores de Campo Grande (MS).

\section{Metodologia da pesquisa}

Esta pesquisa tem abordagem qualitativa, com objetivos descritivos, explicativos e procedimentos colaborativos. Teve como sujeitos professores dos anos iniciais e finais do ensino fundamental da Rede Municipal de Ensino (REME), formados nas diversas áreas, concursados por pelo menos 20 horas e que foram aprovados num processo seletivo simplificado

O levantamento de dados iniciou com o acesso ao projeto do curso de formação continuada e às legislações vigentes da SEMED que envolvem os sujeitos da pesquisa e suas atribuições. Em seguida elaborou-se um questionário no Google Drive com objetivo de investigar se a interação social contribui para o desempenho de alunos e se facilita a produção coletiva e colaborativa em um curso de formação continuada de professores. Paralelamente acessou-se o curso online pelo Moodle para se coletar informações, referentes às interações nos fóruns dos nove módulos do curso, e quanto à 
produção coletiva e colaborativa realizada no terceiro módulo, no espaço da Wiki (http://wiki.semed.capital.ms.gov.br/index.php/P\%C3\%A1gina_principal).

Por último, foi feita uma entrevista individual online, com dois professores mediadores do curso, por meio do bate-papo do Gmail, composta por questões semiestruturadas, a fim de levantar informações sobre planejamento, mediação, função dentro do curso; resultados obtidos, quanto tempo dedicaram ao trabalho; relevância e função do fórum, concepção de interação e características que ajudam na aprendizagem.

Uma vez realizada a entrevista, o tratamento dos dados foi feito, segundo a análise de conteúdo proposta por Bardin (1977, p. 42). Para realizar a análise de conteúdo, primeiramente foi feita a leitura de todos os comentários dos cursistas, no questionário, e das respostas dos professores mediadores, nas entrevistas. Após a leitura foram identificadas e relacionadas as estruturas referentes à interação, que correspondiam ou relacionavam com o objeto da pesquisa (interação).

\section{Descrição e análise dos resultados}

O questionário aplicado traçou o perfil dos sujeitos da pesquisa e suscitou vários aspectos relacionados à interação social realizada durante o curso, por meio do ambiente virtual.

A análise de conteúdo das respostas dos cursistas sobre a interação social sobre qual a importância da interação social no Ambiente Virtual de Ensino e Aprendizagem (Moodle) encontrou quatro categorias de agrupamento das opiniões: um complemento; um compartilhamento e ampliação de saberes com o tutor/mediador; uma troca de experiência entre os pares e uma comunicação que não atende o objetivo do cursista.

Ao analisar o ponto de vista dos professores cursistas quanto ao desenvolvimento de atividades que envolvem a produção coletiva e colaborativa propostas no espaço ambiente Moodle, levantou que a maioria considerou importante a interação entre os colegas mesmo afirmando que as contribuições nem sempre foram de concordâncias.

$\mathrm{Na}$ entrevista com professores mediadores a respeito das interações realizadas pelos e com os cursistas, no contexto de um curso de formação continuada de professores, por meio do AVEA, verificou-se que os professores mediadores destacaram a discussão, a argumentação, a sugestão, os feedbacks, as contribuições, visando auxílio, ajuda cooperação e a agregação de novos conhecimentos.

Em relação a verificar se interação entre os professores cursistas, propicia a produção coletiva e colaborativa, se percebeu que foi confirmado o estímulo dado pela interação para a produção coletiva. Compreende-se que este processo foi facilitado e motivado, pois quanto mais pessoas envolvidas na participação efetiva de uma ação de construção, há menos sobrecarga individual, pelo fato da distribuição de responsabilidades. Assim todos foram corresponsáveis pela produção e pelas múltiplas 
contribuições, o que acabou se tornando rica em pontos de vistas, argumentos, ideias e de embasamentos teóricos que teceram a produção coletiva na wiki.

Nos resultados obtidos foram apontados pelos professores cursistas a falta de interação por parte dos mediadores. Estes dados apontam duas situações: uma que o professor cursista ainda não desenvolveu as habilidades específicas, necessárias para um estudante da $\mathrm{EaD}$, que é a autonomia, autoestudo e planejamento de tempo, se tornando muito dependente do mediador. E a outra se refere ao despreparo do mediador que foi superficial nos feedbacks e/ou ausente nos momentos que o professor cursista mais precisou, pois na educação a distância não se deve deixar os estudantes se sentirem "abandonados".

É por essa razão, que discussões, questionamentos, imagens, esclarecimentos, deduções, argumentos, solicitações e demonstrações são necessárias nas interações sociais. Tudo isso compõem as condições para a produção de conhecimento, já que segundo Vygotski, citado por Duran e Vidal (2007, p.21), são

as situações de interação, e especialmente a atividade conjunta com outras pessoas mais competentes no uso dos instrumentos mediadores (signos ou ferramentas), que comportarão o desenvolvimento individual das capacidades psicológicas humanas. Assim, o pensamento, a atenção e a memória voluntária têm sua origem na vida social ou interindividual.

Dessa forma, as atividades num AVEA podem proporcionar situações de interação em que os envolvidos trabalham em conjunto em prol de um objetivo, que se origina na convivência social para depois internalizar e concretizar o desenvolvimento individual.

\section{Considerações finais}

A questão norteadora da pesquisa foi se a interação social contribui para o desempenho dos cursistas bem como para a produção coletiva e colaborativa, num fórum de um AVEA, em um curso de formação continuada de professores. Os dados, aliados à teoria e ao levantamento bibliográfico sobre o tema permitem afirmar que a interação permeia todo o processo educativo, e no caso desta pesquisa, na formação continuada de professores. Essas relações foram proporcionadas pelos mediadores, por meio dos recursos do Moodle, especialmente pelo fórum e wiki.

Porém, para que houvesse um processo dinâmico que propiciasse a produção coletiva e colaborativa dos cursistas, os professores mediadores planejaram e estabeleceram estratégias metodológicas utilizando-se dos recursos do Moodle para a realização de atividades que viabilizaram a interação social para que os cursistas se envolvessem e não desistissem do curso.

Diante disso, constatou-se que, de forma geral, a interação social proporcionada na formação contribuiu para o desempenho dos cursistas, bem como para as produções 
coletivas e colaborativas. A pesquisa esclareceu alguns dados sobre a problemática levantada, mas também levantou outras situações que podem ser mais exploradas e investigadas com mais profundidade. Dentre elas, pode-se citar a questão de como a motivação e o testemunho dos cursistas em relação à contribuição da interação social na produção colaborativa e coletiva, bem como as queixas quando o mediador não fornece os feedbacks ou quando a comunicação entre cursista e mediador não alcança o objetivo esperado.

Destaca-se dessa forma a valorização e a importância da interação social nos cursos de formação continuada de professores, visto que todos os envolvidos e os próprios registros feitos nos ambientes enfatizam e concretizam essa relação, a fim de alcançar o seu objetivo na formação e, consequentemente, obterem um bom desempenho no curso.

\section{Referências}

BARDIN, Laurence. Análise de Conteúdo. Tradução de Luís Antero Reto e Augusto Pinheiro. São Paulo: Martins Fontes, 1977.

DURAN, D. , VIDAL, V. Aprendizagem entre iguais: da teoria à prática. Tradução Ernani Rosa. Porto Alegre: Artmed, 2007.

FERNANDEZ, Jany Baena. Contribuição da interação no ambiente virtual de ensino e aprendizagem no desempenho de alunos de um curso de formação continuada de professores. Florianópolis, 2013. Monografia (especialização) - Curso de Especialização em Gestão e Docência em Educação a Distância. Universidade Federal de Santa Catarina, Centro Sócio-Econômico.

GIL, A. C. Como elaborar projetos de Pesquisa. 5a ed. São Paulo: Atlas, 2010.

KENSKI, V. M. Novos Processos de interação e comunicação no ensino mediado pelas tecnologias. Cadernos Pedagogia Universitária, USP. Adaptado do capítulo 8 do livro "Tecnologias e ensino presencial e ensino a distância", de Vani Moreira Kenski. 2008.

Processos de interação e comunicação mediados pelas tecnologias. In: ROSA, D., SOUZA, V. (orgs.). Didática e práticas de ensino: interfaces com diferentes saberes e lugares formativos. Rio de Janeiro: DP\&A, 2002.TOSTES, S. C.. Estratégias mediadoras no ambiente virtual. Rev. bras. linguist. apl.[online]. 2011, vol.11, n.1, pp. 177-197. Disponível em: $<$ http://www.scielo.br/scielo.php?pid=S1984$\underline{63982011000100010 \& \text { script=sci_abstract\&tlng=pt }>\text { Acesso em: } 10 \backslash 5 \backslash 2013 .}$

VYGOTSKI, L. S. A formação social da mente: o desenvolvimento dos processos psicológicos superiores. Org. Michel Cole [et al]; $7^{\mathrm{a}}$ ed. São Paulo: Martins Fontes, 2010 . 